\title{
Phase formation and magnetocaloric effect in (Pr,Nd)-Fe alloys prepared by rapidly quenched method
}

\author{
Dan Nguyen ${ }^{1,2, *}, H a$ Nguyen ${ }^{2,3}$, An Nguyen $^{3}$, Yen Nguyen ${ }^{1,2}$, Thanh Pham ${ }^{1,2}$, Victor Koledov ${ }^{4}$, Alexander Kamantsev ${ }^{4}$, \\ Alexey Mashirov", Thanh Tran ${ }^{1,5}$, Hau Kieu $^{5}$ and Seong $\mathrm{Yu}^{5}$ \\ ${ }^{1}$ Institute of Materials Science, Vietnam Academy of Science and Technology, 18 Hoang Quoc Viet, Ha Noi, Viet Nam \\ ${ }^{2}$ Graduate University of Science and Technology, Vietnam Academy of Science and Technology, 18 Hoang Quoc Viet, Ha Noi, Viet Nam \\ ${ }^{3}$ Hong Duc University, 565 Quang Trung, Dong Ve, Thanh Hoa, Viet Nam \\ ${ }^{4}$ Kotelnikov Institute of Radio-engineering and Electronics of RAS, Moscow, Russia \\ ${ }^{5}$ Department of Physics, Chungbuk National University, Cheongju 361 - 763, South Korea
}

\begin{abstract}
In this work, $\operatorname{Pr}_{2-x} \mathrm{Nd}_{x} \mathrm{Fe}_{17}(\mathrm{x}=0$ - 2) ribbons with thickness of about $15 \mu \mathrm{m}$ were prepared by melt-spinning method. The alloy ribbons were then annealed at different temperatures $\left(900-1100^{\circ} \mathrm{C}\right)$ for various time $(0.25-2 \mathrm{~h})$. The formation of the $(\mathrm{Pr}, \mathrm{Nd})_{2} \mathrm{Fe}_{17}(2: 17)$ crystalline phase in the alloys strongly depends on the $\mathrm{Pr} / \mathrm{Nd}$ ratio and annealing conditions. Annealing time for the completed formation of the $2: 17$ phase in the rapidly quenched ribbons is greatly reduced in comparison with that of bulk alloys. Curie temperature, $\mathrm{T}_{\mathrm{C}}$, of the alloys can be controlled in room temperature region by changing $\mathrm{Pr} / \mathrm{Nd}$ ratio. Maximum magnetic entropy change $\left(\left|\Delta \mathrm{S}_{\mathrm{m}}\right|_{\max }\right)$ and full width at haft the maximum peak (FWHM) of the

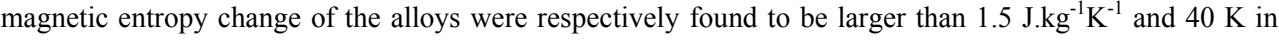
room temperature region with magetic field change $\Delta \mathrm{H}=12 \mathrm{kOe}$.
\end{abstract}

\section{Introduction}

Magnetocaloric effect (MCE) is defined as the adiabatic temperature change of a magnetic material upon the application of a magnetic field. The MCE of the material is of interest in research by virtue of its potential application in the field of magnetic refrigeration. The magnetic refrigeration bases on the principle of magnetic entropy change of the material. To have large magnetic cooling efficient, the MCE of the material should be large (magnetic entropy change $\Delta \mathrm{S}_{\mathrm{m}}$, adiabatic temperature variation $-\Delta \mathrm{T}_{\mathrm{ad}}$ and refrigerant capacity - RC should be large) with low field change. In later years, some materials have large magnetocaloric effect (so-called giant magnetocaloric effect - GMCE) were discovered, such as: rare earthcontaining alloys, As-containing alloys, La-containing alloys, Heusler alloys, $\mathrm{Fe}$ and $\mathrm{Mn}$ based rapidly quenched alloys, the ferromagnetic perovskite maganites... [1-8]. Among them, alloys containing rare earth elements (RE) such as $\mathrm{Gd}, \mathrm{Pr}, \mathrm{Nd}$... are considered as very attractive systems [9-15]. In particular, Fe-rich $\mathrm{RE}_{2} \mathrm{Fe}_{17}$ alloys exhibit ferromagnetic order with high values for the $\mathrm{Fe}$ magnetic moment, and the Curie temperature, $\mathrm{T}_{\mathrm{C}}$, around room temperature in the case of $\mathrm{Pr}$ and $\mathrm{Nd}[16,17]$. Moreover, these alloys show large MCE with the maximum magnetic entropy change $\left(\left|\Delta \mathrm{S}_{\mathrm{m}}\right|_{\max }\right)$ of $6 \mathrm{~J}^{\mathrm{kg}}{ }^{-1} \mathrm{~K}^{-1}$ under $50 \mathrm{kOe}$ magnetic field at room temperature (for $\mathrm{RE}=\mathrm{Nd}$, Pr) $[18,19]$. Although $\Delta \mathrm{S}_{\mathrm{m}}$ of $(\mathrm{Nd}, \mathrm{Pr})_{2} \mathrm{Fe}_{17}$ alloys is lower than that of Gd-SiGe alloys [20,21] and La-Fe-Si alloys [22], the $\mathrm{Pr}_{2} \mathrm{Fe}_{17}$ and $\mathrm{Nd}_{2} \mathrm{Fe}_{17}$ alloys have GMCE around room temperature, broad $\Delta \mathrm{S}_{\mathrm{m}}$ peak around the Curie temperature, low cost and no toxicity, making them become potential candidates for magnetic refrigeration [23-25]. However, there are still some problems in fabricating $(\mathrm{Nd}, \mathrm{Pr})_{2} \mathrm{Fe}_{17}$ single phase and regulating magnetic phase transition for these alloys. Thus, in this paper, we present the results of study on dependence of structure, magnetic properties and magnetocaloric effect on heat treatment and $\mathrm{Nd} / \mathrm{Pr}$ ratio of $\mathrm{Pr}_{2-\mathrm{x}} \mathrm{Nd}_{\mathrm{x}} \mathrm{Fe}_{17}$ (with $\mathrm{x}$ $=0,1$ and 2) alloy ribbons.

\section{Experiment}

Ingots with nominal compositions of $\operatorname{Pr}_{2-x} \mathrm{Nd}_{\mathrm{x}} \mathrm{Fe}_{17}$ (x $=0,1$ and 2) were prepared from pure components of $\mathrm{Pr}$, $\mathrm{Nd}$ and $\mathrm{Fe}$ on an arc-melting furnace to ensure their homogeneity. The ribbons were then fabricated on a single wheel melt-spinning system. The quenching rate of the ribbons could be changed by changing tangential velocity, v, of the copper wheel. In this study, the ribbons were prepared with $\mathrm{v}=40 \mathrm{~m} / \mathrm{s}$. The ribbons samples with the $\sim 3 \mathrm{~mm}$ width and $\sim 15 \mu \mathrm{m}$ thickness were obtained. Subsequently, the ribbons were annealed from $900^{\circ} \mathrm{C}$ to $1000^{\circ} \mathrm{C}$ for various times. All of the arcmelting, melt-spinning and annealing process were performed under Ar atmosphere to avoid oxygenation. Structure of the ribbons was analyzed by X-ray diffraction (XRD). Magnetization measurements in the temperature range of $77-600 \mathrm{~K}$ were performed on a

\footnotetext{
*Corresponding author: dannh@ims.vast.ac.vn
} 
vibrating sample magnetometer (VSM). The values of magnetic entropy change $\Delta \mathrm{S}_{\mathrm{m}}$ which caused by a variation of applied magnetic field was calculated via:

$$
\Delta \mathrm{S}_{\mathrm{m}}=-\int_{0}^{\mathrm{H}}\left(\frac{\partial \mathrm{M}}{\partial \mathrm{T}}\right) \mathrm{dH}
$$

\section{Result and discussion}

(a)
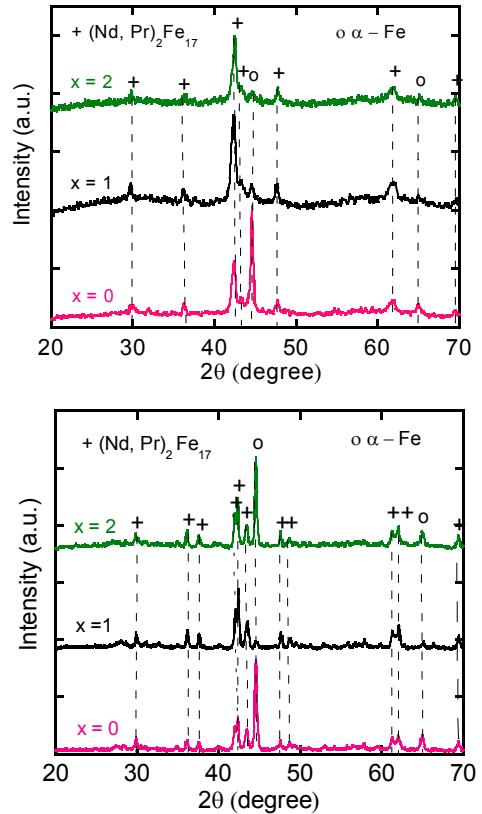

(b)

Fig. 1. $X R D$ patterns of $\operatorname{Pr}_{2-x} \mathrm{Nd}_{x} \mathrm{Fe}_{17}(\mathrm{x}=0,1$ and 2) ribbons before (a) and after annealing (b).

Figure 1 is the XRD patterns of the $\operatorname{Pr}_{2-\mathrm{x}} \mathrm{Nd}_{\mathrm{x}} \mathrm{Fe}_{17}(\mathrm{x}=0,1$ and 2) alloy ribbons. The results show that the structure of the ribbons clearly depends on Nd-concentration. There are two diffraction peaks of the XRD patterns corresponding to $\alpha-\mathrm{Fe}$ phase. Other peaks are of $(\mathrm{Nd}, \mathrm{Pr})_{2} \mathrm{Fe}_{17}(2: 17)$ phase. Intensity of diffraction peaks of $\alpha$-Fe phase is reduced with increasing Nd-concentration. This is important in controlling the formation of undesirable phases of the material. Annealing process has also clearly influenced on the structure of the alloy. After annealing, more diffraction peaks characterizing $(\mathrm{Nd}, \mathrm{Pr})_{2} \mathrm{Fe}_{17}$ phase are formed. Intensity of these peaks is higher and sharper, especially, in the sample with $x=1$. It should be noted that intensity of diffraction peaks of $\alpha-\mathrm{Fe}$ is weakened with $\mathrm{Nd} / \mathrm{Pr}$ ratio of 1 . Thus, the sample is relatively single phase with appropriate Nd-concentration. This will affect the magnetic properties and MCE of the alloy as presented below the alloy.

To determine the coercivity, $\mathrm{H}_{\mathrm{c}}$, and the saturation magnetization, $\mathrm{M}_{\mathrm{s}}$, of the samples, we measured hysteresis loops of $\operatorname{Pr}_{2-\mathrm{x}} \mathrm{Nd}_{\mathrm{x}} \mathrm{Fe}_{17}(\mathrm{x}=0,1$ and 2) ribbons at room temperature (figure 2). The results show that all the samples manifest the soft magnetic behavior. The coercivity of the samples is smaller than 160 Oe. Figure 3 presents the dependence of the saturation magnetization on Nd-concentration. From this figure, we see that the $\mathrm{M}_{\mathrm{s}}$ of the samples is quite high, above $50 \mathrm{emu} / \mathrm{g}$. Besides, the saturation magnetization is reduced with increasing $\mathrm{Nd}$ concentration (or reducing Pr-concentration). In detail, the
$M_{s}$ value of the samples with $x=0,1$ and 2 is 105,101 and $54 \mathrm{emu} / \mathrm{g}$, respectively.

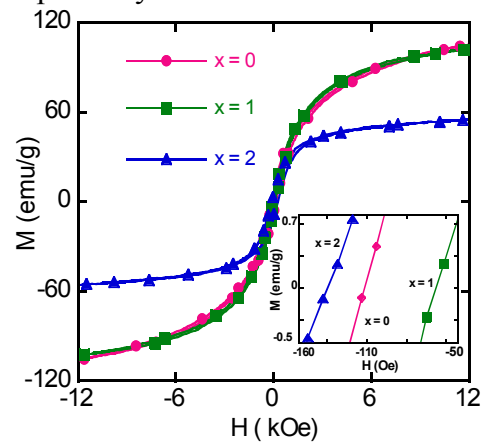

Fig. 2. $M(H)$ loops at room temperature (the inset enlarges the loops at low magnetic field) of $\mathrm{Pr}_{2-\mathrm{x}} \mathrm{Nd}_{\mathrm{x}} \mathrm{Fe}_{17}(\mathrm{x}=0,1$ and 2$)$ ribbons.

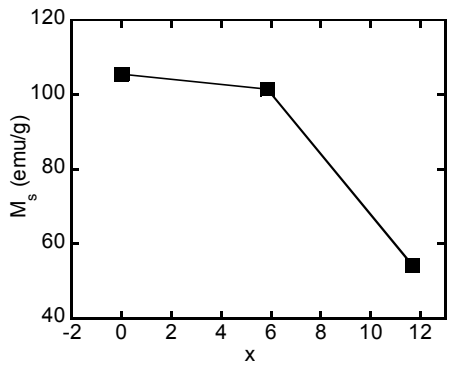

Fig. 3. The dependence of the saturation magnetization on $\mathrm{Nd}$ concentration (x) of $\operatorname{Pr}_{2-x} N_{x} \mathrm{Fe}_{17}(\mathrm{x}=0,1$ and 2$)$ at room temperature.

In order to investigate influence of annealing process on magnetic properties of the alloy, we measured thermomagnetization curves of the samples before and after annealing. Figure 4 reveals the dependence of reduced magnetization on temperature of the asquenched ribbons in an applied magnetic field of 100 Oe. In as-quenched state, the samples manifest the multiphase behavior. These ribbons have magnetic phase transitions in the temperature range of $250-450 \mathrm{~K}$. After the first transition, the magnetization of these ribbons does not decrease to zero, but maintains values characterizing the other crystalline phase. The $\mathrm{x}=0$ sample has a magnetic phase transition at about $300 \mathrm{~K}$. The $\mathrm{x}=1$ sample owns the first phase transition at $380 \mathrm{~K}$ and the second phase transition at $425 \mathrm{~K}$. Similarly, the $\mathrm{x}$ $=2$ sample has a phase transition at $370 \mathrm{~K}$ and the next phase transition at $440 \mathrm{~K}$. With purpose to create single phase for the alloy, heat treatment was carried out. Figure 5 is the reduced thermomagnetization curves in an applied field of 100 Oe of $\operatorname{Pr}_{2-x} \mathrm{Nd}_{x} \mathrm{Fe}_{17}(\mathrm{x}=0,1$ and 2) alloy ribbons after annealing at $900^{\circ} \mathrm{C}$ for $2 \mathrm{~h}$. The results show that the magnetic properties are considerably improved after annealing. Specially, the ferromagnetic-paramagnetic (FM-PM) transition of the $\mathrm{x}=1$ sample is quite sharp. According to XRD patterns of the samples (figure 7), the sample with $\mathrm{x}=0$ is almost single phase with the 2:17 structure after annealing. As for the samples with $\mathrm{x}=0$ and $\mathrm{x}=2$, diffraction peaks of the $\alpha$-Fe crystalline phase are comparable with those of the $2: 17$ phase. That is reason for the single magnetic phase feature of the sample with $\mathrm{x}=1$ and the multi-magnetic phase behavior of the 
samples with $x=0$ and $x=2$. Curie temperature of the $\alpha$ Fe phase is higher than that of the 2:17 phase leading to the maintenance of magnetization in high temperature region after the transition of the 2:17 magnetic phase near room temperature.

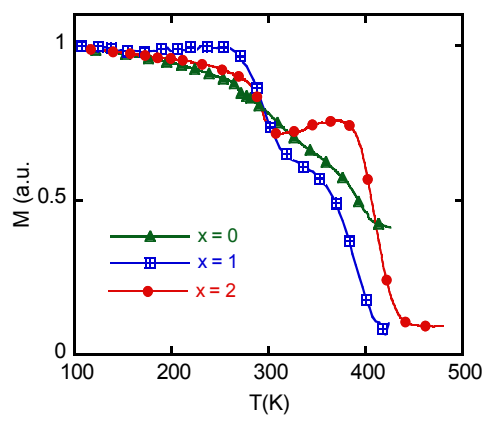

Fig. 4. Reduced thermomagnetization curves in an applied magnetic field of $100 \mathrm{Oe}$ of $\operatorname{Pr}_{2-\mathrm{x}} \mathrm{Nd}_{\mathrm{x}} \mathrm{Fe}_{17}(\mathrm{x}=0,1$ and 2) asquenched ribbons.

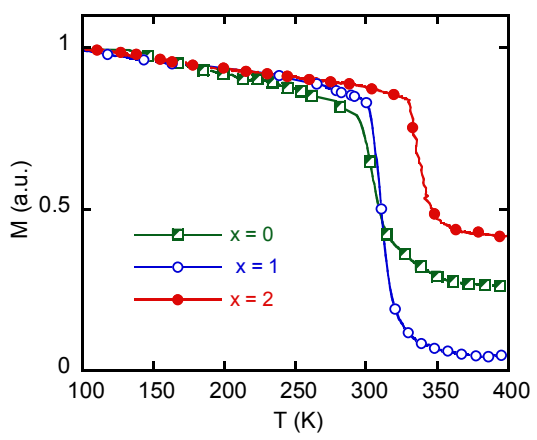

Fig. 5. Reduced thermomagnetization curves in an applied magnetic field of $100 \mathrm{Oe}$ of $\mathrm{Pr}_{2-\mathrm{x}} \mathrm{Nd}_{\mathrm{x}} \mathrm{Fe}_{17}$ ( $\mathrm{x}=0,1$ and 2) ribbons after annealing at $900^{\circ} \mathrm{C}$ for $2 \mathrm{~h}$.

Figure 6 displays the reduced thermomagnetization curves in an applied magnetic field of $100 \mathrm{Oe}$ of $\mathrm{Pr}_{2}$ ${ }_{x} \mathrm{Nd}_{\mathrm{x}} \mathrm{Fe}_{17}$ ( $\mathrm{x}=0,1$ and 2$)$ annealed at different temperatures $\left(900-1100^{\circ} \mathrm{C}\right)$ for various time $(0.25-2$ h). From obtained results, we see that the $x=1$ sample annealed at $950^{\circ} \mathrm{C}$ for $2 \mathrm{~h}$ has the sharp phase transition. The Curie temperature $\left(\mathrm{T}_{\mathrm{C}}\right)$ of this sample is $310 \mathrm{~K}$. In particular, its magnetization is almost zero after the first magnetic transition. This shows that this sample is almost single magnetic phase transition.

From figure $6 \mathrm{~b}$, it is apparent that the $\mathrm{x}=1$ sample annealed at $950^{\circ} \mathrm{C}$ for $2 \mathrm{~h}$ has a quite strong magnetic phase transition, revealing the possibility of a large MCE. On the other hand, the $\mathrm{T}_{\mathrm{C}}$ of this sample is around room temperature. Therefore, with the goal of finding magnetocaloric materials that possess magnetic transition temperature close to room temperature, we chose $\mathrm{NdPrFe}_{17}$ ribbon annealed at $950^{\circ} \mathrm{C}$ for $2 \mathrm{~h}$ to investigate its $\mathrm{MCE}$. We calculated magnetic entropy change $\left(\Delta \mathrm{S}_{\mathrm{m}}\right)$ basing on thermomagnetization curves of this ribbon at various magnetic fields ranging from 0.01 to $12 \mathrm{kOe}$ (figure 7). From the thermomagnetization curves for the samples in various magnetic fields, we can deduce the magnetization versus magnetic field, $M(H)$, at various temperatures (figure 8). According to previous results $[26,27]$, to check this derivation procedure, we compared data deduced from thermomagnetization curve with data of virgin magnetization ones and we found that the data obtained from the two different ways are coincided. Then, the magnetic entropy change, $\Delta S_{m}$, is determined from $\mathrm{M}(\mathrm{H})$ data by using equation (1).

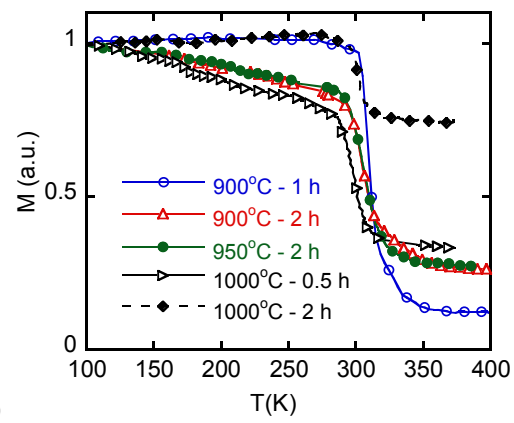

(a)

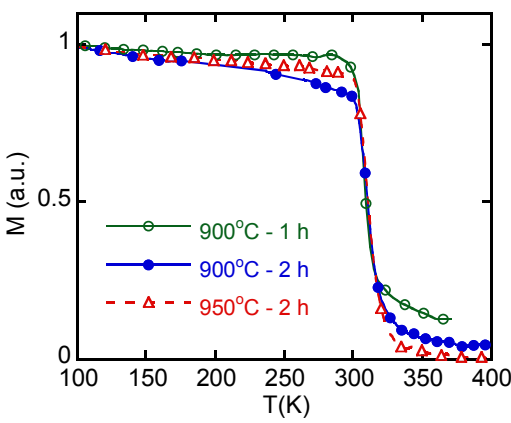

(b)

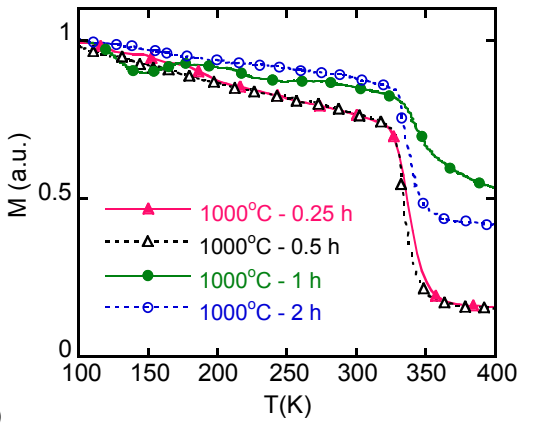

Fig. 6. Reduced thermomagnetization curves of $\operatorname{Pr}_{2} \mathrm{Fe}_{17}(\mathrm{a})$, $\mathrm{NdPrFe} e_{17}$ (b) and $\mathrm{Nd}_{2} \mathrm{Fe}_{17}$ (c) ribbons after annealing at different temperatures for various time.

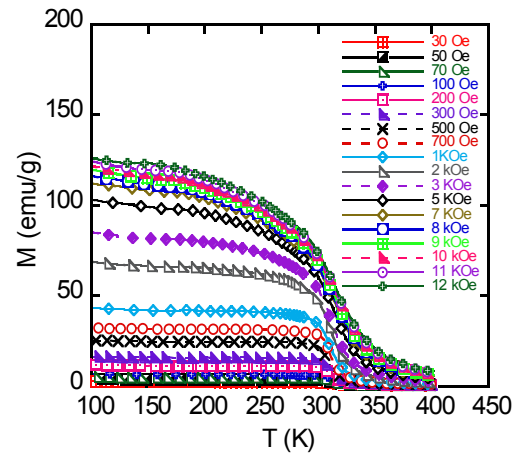

Fig. 7. Thermomagnetization curves in various magnetic field of $\mathrm{NdPrFe}_{17}$ ribbon. 


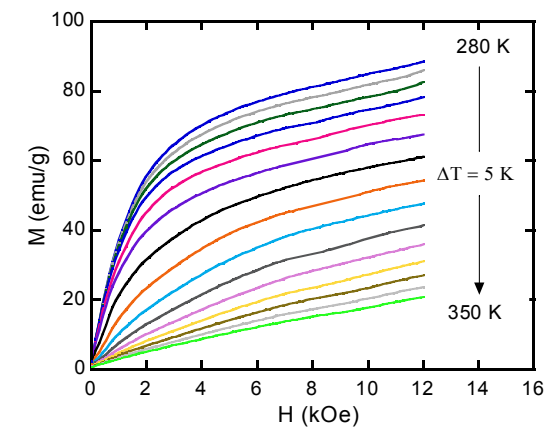

Fig. 8. Magnetization versus magnetic field at various temperatures deduced from thermomagnetization curves of $\mathrm{PrNdFe}_{17}$ ribbon.

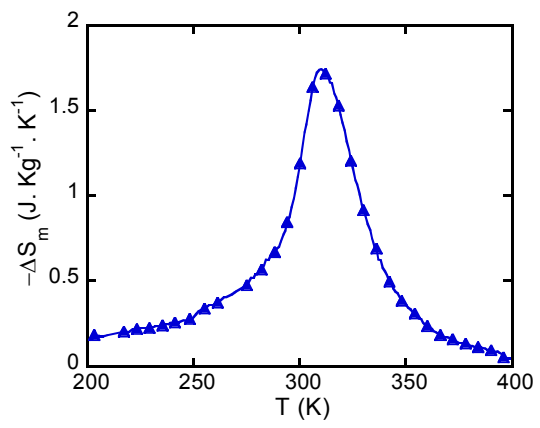

Fig. 9. $-\Delta \mathrm{S}_{\mathrm{m}}(\mathrm{T})$ curves (with $\Delta \mathrm{H}=12 \mathrm{kOe}$ ) of $\operatorname{PrNdFe}_{17}$ ribbon.

Figure 9 is the temperature dependence of $-\Delta S_{m}$ of $\mathrm{NdPrFe}_{17}$ ribbon after annealing at $950^{\circ} \mathrm{C}$ for $2 \mathrm{~h}$ in a magnetic field change of $0-12 \mathrm{kOe}$. The maximum magnetic entropy change, $\left|\Delta \mathrm{S}_{\mathrm{m}}\right|_{\max }$, is $1.72 \mathrm{~J}_{\mathrm{kg}}{ }^{-1} \cdot \mathrm{K}^{-1}$ at $310 \mathrm{~K}$. The refrigerant capacity $(\mathrm{RC})$ of the samples, which is defined as product of maximum entropy change $\left(\left|\Delta \mathrm{S}_{\mathrm{m}}\right|_{\max }\right)$ and full width at half maximum $\left(\delta \mathrm{T}_{\mathrm{FWHM}}\right)$ of entropy change peak, was also calculated. The $\delta \mathrm{T}_{\mathrm{FWHM}}$ value is also mentioned as the working temperature range of magnetic refrigerant. The working temperature range of the alloys is about $40 \mathrm{~K}$. The refrigerant capacity, which is determined for $\mathrm{NdPrFe}_{17}$ ribbon, is 69 $\mathrm{J} / \mathrm{kg}$. This value is comparable to higher than that of $\mathrm{Pr}_{2} \mathrm{Fe}_{17}$ and $\mathrm{Nd}_{2} \mathrm{Fe}_{17}$ alloys [11, 18, 19].

\section{Conclusion}

The influence of $\mathrm{Pr} / \mathrm{Nd}$ ratio and annealing process on structure, magnetic properties and magnetocaloric effect of (Pr,Nd)-Fe alloy ribbons has been investigated. The formation of $(\mathrm{Pr}, \mathrm{Nd})_{2} \mathrm{Fe}_{17}$ crystalline phase strongly depends on $\mathrm{Pr} / \mathrm{Nd}$ ratio and annealing conditions. $\left(\mathrm{Pr}, \mathrm{Nd}_{2} \mathrm{Fe}_{17}\right.$ phase is dominantly formed in the sample after annealing. Magnetic properties of the alloy changed markedly with annealing temperature and time. The sample with $\mathrm{Pr} / \mathrm{Nd}$ ratio of 1 is relatively single phase after annealing. The maximum magnetic entropy change $\left(\left|\Delta \mathrm{S}_{\mathrm{m}}\right|_{\max }\right)$ of $\mathrm{NdPrFe}_{17}$ ribbon was determined to be $1.72 \mathrm{~J}_{\mathrm{kg}}{ }^{-1} \cdot \mathrm{K}^{-1}$ at $310 \mathrm{~K}$ with magnetic field change $\Delta \mathrm{H}=12 \mathrm{kOe}$.

This work was supported by Vietnam Academy of Science and Technology under grant No. VAST.HTQT.NGA.05/17-18 and Russian Foundation for Basic Research under grant No. 17-58-
540002. A part of the work was done in Key Laboratory for Electronic Materials and Devices and Laboratory of Magnetism and Superconductivity, Institute of Materials Science, Vietnam.

\section{References}

1. X. Zhou, W. Li, H.P. Kunkel, G. Williams, J. Phys.: Condens. Matter 16, L39 (2004).

2. X. Zhang, B. Zhang, S. Yu, Z. Liu, W. Xu, G. Liu, J. Chen, Z. Cao, G. Wu, Phys. Rev. B: Condens. Matter 76, 132403 (2007).

3. W. Y. Tian, B. H. Yang, P. M. Xiang, Z. D. Qian, Wang Wei Hua, Sci. China. Ser. G-Phys. Mech. Astron 51, 337 (2008).

4. L. Min, B. Yu, J. Cent. South Univ. Technol. 16, 1 (2009).

5. V.K. Sharma, M.K. Chattopadhyay, J. Phys. D: Appl. Phys. 43, 225001 (2010).

6. E. Yüzüak, B. Emre, Y. Elerman, A. Yüce, Chinese Phys. B, 19, 057501 (2010).

7. M. Klimczak, E. Talik, J. Phys.: Conf. Ser. 200, 092009 (2010).

8. S.P. Mathew, S.N. Kaul, A.K. Nigam, A.C. Probst, R. Birringer, J. Phys.: Conf. Ser. 200, 072047 (2010).

9. J.J. Croat, J. Appl. Phys. 52, 2509 (1981).

10. J.L. Sánchez Llamazares, M.J. Pérez, P. Aslvarez, J.D. Santos, M.L. Sasnchez, B. Hernando, J.A. Blanco, J. Sasnchez Marcos, P. Gorria, J, Alloys Compd. 483, 682 (2009).

11.P. Alvarez, J. Sánchez-Marcos, J.L Sanchez Llamazares, V. Franco, M. Reiffers, J.A. Blanco and P. Gorria, 14th Czech and Slovak Conference on Magnetism, Košice, Slovakia, July 6-9 (2010).

12. H. Chen, Y. Zhang, J. Han, H. Du, C. Wang, Y.C. Yang, J. Magn. Magn. Mat. 320, 1382 (2008).

13. Z.G. Zheng, X.C. Zhong, H.Y. Yu, V. Franco, Z.W. Liu, J. Appl. Phys. 111, 07A922 (2012).

14. X.C. Zhong, P.F. Tang, Z.W. Liu, D.C. Zeng, Z.G. Zheng, J. Appl. Phys. 111, 07A919 (2012).

15. Y. K. Fang, C.H. Lai, C.C. Hsieh, X.G. Zhao, H.W. Chang, W.C. Chang and W. Li, J. Phys. Conf. Series 266, 012002 (2011).

16. K.H.J. Buschow, Rep. Prog. Phys. 40, 1179 (1977).

17. F. Weitzer, K. Hiebl, P.J. Rogl, Appl. Phys. 65, 4963 (1989).

18. S. Yu. Dan'kov, V.V. Ivtchenko, A.M. Tishin, Jr.K.A. Gschneidner, V.K. Pecharsky, Adv. Cryog. Eng. 46, 397 (2000).

19. K. Mandal, A. Yan, P. Kerschl, A. Handstein, O. Gutfleisch, K.H. Müller, J. Phys. D 37, 2628 (2004).

20. O. Tegus, E. Bruck, K.H.J. Buschow, F.R. de Boer, Nature 415, 150 (2002).

21. V. Provenzano, A.J. Shapiro, R.D. Shull, Nature 429, 853 (2004).

22. A. Fujita, S. Fujieda, Y. Hasegawa, K. Fukamichi, Phys. Rev. B 67, 104416 (2003).

23. A.M. Tishin, Y.I. Spichkin, The magnetocaloric effect and its applications (Bristol: IOP Publishing, 2003).

24. Gorria P., J.L. Sánchez Llamazares, P. Alvarez, M.J. Pérez, J Sánchez Marcos, J.A. Blanco, J. Phys. D: Appl. Phys. 41, 192003 (2008).

25. V. Franco, Annu. Rev. Mater. Res. 42, 305 (2012).

26. N.H. Yen, P.T. Thanh, N.H. Duc, T.D. Thanh, T.L. Phan, S.C. Yu, N.H. Dan, Adv. Nat. Sci.: Nanosci. Nanotechnol. 4, 025018 (2013).

27. N.H. Dan, N.H. Duc, T.D. Thanh, N.H. Yen, P.T. Thanh, N.A. Bang, D.T.K. Anh, T.L. Pham, S.C. Yu, J. Korean Phys. Soc. 62, 1715 (2013). 